\title{
Suitability of herbal pesticides, turmeric and neem, in repelling dry fish insect Necrobia sp. adult
}

\author{
U. J. Lithi, M. N. Hassan, M. M. Hossain and A. A. K. M. Nowsad \\ Department of Fisheries Technology, Bangladesh Agricultural University, Mymensingh-2202, Bangladesh, E-mail: \\ jahanulfat@yahoo.com
}

\begin{abstract}
Repellency effect of turmeric and neem was investigated against the mite Necrobia sp. and field doses were determined on the basis of their repellency, keeping quality, insect occurrence and sensory evaluation of turmeric and neem treated dry fish and their cooked products. Turmeric and neem were used in three forms, viz., i. extract, ii. powder and iii. pellet. The concentrations tested for turmeric and neem extracts were $2 \%, 3 \%, 4 \%$ and $3 \%, 5 \%, 7 \%$, respectively, those of both powders were 1.0\%, 1.5\% and 2.0\% and both pellets were 1, 2, 3 pieces on $100 \mathrm{~g}$ dry fish. The order of repellency among three products were: extract> powder> pellet. Turmeric extract and powder were more repellent than neem extract and powder. The color, odor, texture and general appearance of the untreated control and treated dry fish were almost similar after 2 month of storage at room temperature. After 4 month of storage, the sensory attributes like odor, texture and general appearance and the occurrence of insects in control dry fish fell down significantly but those in treated dry fish were mostly unchanged. Study suggested that turmeric at the rate of $3 \%$ extract or $1.5 \%$ powder or neem at the rate $5 \%$ extract or $1.5 \%$ powder could be suitable field doses for application of such herbs in dry fish directly to repel insects while storing the products.
\end{abstract}

Keywords: Dry fish, Insect, Pesticide, Repellency

\section{Introduction}

Dry fish is an important source of animal protein and people eat dry fish as a tasty dish all over the country. For this reason about $20 \%$ of total fish caught are sun dried and mostly consumed in the domestic market annually (DoF, 2010). Dry fish is also exported, that earns a handsome amount of foreign currency. Annual export of dry fish ranks third in the export of fishery products, accounting 1400 to 1600 metric tons and earning about Tk. 600 crore as foreign currency (BBS, 2005). Dry fish are contaminated by both insects and insecticides comprise about $60 \%$ of the total dried products that is considered to be unfit for human consumption (Neuschler, 1998).

Major problems associated with the sun-drying of fish is the infestation of the products by the blow fly and beetle larvae (Nowsad, 2005). Under warm and humid condition, sun-dried fish rapidly become infested by blowfly larvae (Kordyl, 1976). In tropical climates under highly humid condition, heavy infestation of unsalted dry fish by beetles may cause up to 30\% loss of the products (Bala and Mondol, 2001). Generally, two major infestations damage the dry fish products: i. larvae (maggots) of several species of blowfly (Diptera) infestation during the early stages of the drying; and ii. beetle (Dermestes sp. - both larvae and adult) and mite (Nacrobia sp.) infestations during storage and distribution. These insects are generally associated with dry fish especially during storage, transportation and marketing (Don-Pedro, 1989).

Compared to synthetic chemical pesticides, plant products are generally considered to be safe and nontoxic to mammals, birds and fish (Ascher, 1993) and cause less disturbance to ecosystems than chemical insecticides (Sundaram, 1996). There are about 2000 plant species seem to possess pest control properties (Xie et al., 1995). Botanical insecticides are the alternative to synthetic chemical pesticides since these compounds are biodegradable and less persistent in the environment. In recent laboratory experiments, plants like neem and turmeric had shown effective repellent effects on beetles and mites of dried fish (Nowsad, 2005). The study was therefore, designed to determine the efficacy of neem and turmeric in extracts, powder and pellets in repelling Necrobia mite. Field dosages of these herbs against Nacrobia sp. (adult) was determined and quality of neem and turmeric treated dry fish and their cooked products was also assessed. 


\section{Materials and Methods}

Experiment was conducted in the Processing and Microbiology Laboratories of the Department of Fisheries Technology, Bangladesh Agricultural University, Mymensingh, during the period between August 2009 and September 2010.

\section{Preparation of plant extract}

Fresh neem leaves were collected from Bangladesh Agricultural University campus. Dried turmeric was purchased from local market. Water extracts were prepared by boiling $\left(90^{\circ} \mathrm{C}\right.$ for $\left.60 \mathrm{~min}\right) 1 \mathrm{~kg}$ of green neem leaves in 2 litres of water and $200 \mathrm{~g}$ of turmeric powder in 2 litres of water. The extracts were filtered and cooled, made the volume of $500 \mathrm{ml}$ each in separate measuring dark glass bottles and kept in the refrigerator for bioassay test (Mondol, 2008).

\section{Preparation of plant powder}

Neem and turmeric powders were prepared by pulverizing the dried plant portions with the help of a grinder. The dusts were passed through a 25-mesh diameter sieve to obtain fine and uniform powder and preserved in airtight plastic container until further use.

\section{Preparation of pellet}

Pellets of neem and turmeric were prepared by mixing $90 \mathrm{~g}$ of neem and turmeric powders separately with $10 \mathrm{~g}$ of flour and required amount of water. Flour was used as a binder. The dough was flattened into a sheet of $2 \mathrm{~mm}$ thickness and cut by using a dice to get a convenient size and shape of flat pellet.

\section{Collection and rearing of insect}

The test insects, Necrobia sp. (adult) were collected from the dry fish markets of Mymensingh town. The insects were reared with chopped dry fish in plastic jars and maintained in the laboratory of the Faculty of Fisheries, BAU at $27-30^{\circ} \mathrm{C}$.

\section{Preparation of dried fish}

Fresh wet jatpunti (Puntius sophore) were scaled, gutted and washed with clean water and sundried on open rack for 3-4 days so that the moisture level reduced to less than $16 \%$. During drying, aqueous extract of turmeric at the rate of 2, 3 and $4 \%$ and that of neem at the rate of 3, 5 and $7 \%$ were sprayed over the fish by a hand sprayer. After drying, the products were sealed in a polythene bag to avoid absorption of moisture and kept in a refrigerator until use.

\section{Insect bioassays}

Insect bioassay was conducted in the Microbiology Laboratory of the Department of Fisheries Technology, BAU at 27 to $30^{\circ} \mathrm{C}$ to determine the repellency of turmeric and neem against Necrobia sp. (adult).

\section{Repellency test}

Repellency test was conducted for both adult of Necrobia sp. according to the method of Talukder and Howse (1995). Dry fish treated with turmeric and neem extracts at different concentrations were used to determine the repellency rate of insects. Crushed dry fish in the petridish were divided into two parts with a clear line space maintained along the middle of petridish. One part was treated with prescribed dose of neem or turmeric extracts and the other control part was not treated. For turmeric and neem powders, three dose variables for each of turmeric and neem powders, viz., 1.0, 1.5 and 2.0\%, were spread over the treated dry fish part. For turmeric and neem pellets, three dose variables viz., 1, 2 and 3 pieces of pellets were kept over the treated dry fish portion in the petridish and an untreated control part was maintained. Ten insect were released at the middle clear line of each petridish and the petridish was covered. The insects moved or present on treated and untreated part were counted at hourly intervals up to five hours. Each experiment was replicated three times. 
The data were expressed as percentage repulsion (PR \%) by the following formula:

$\mathrm{PR}(\%)=(\mathrm{NC}-50) \times 2$

Where, $\mathrm{NC}=$ The percentage of insects present in the control half.

Positive (+) values expressed repellency and negative (-) values expressed attractency.

\section{Application of extract, powder and pellet form of turmeric and neem}

Extracts, powders and pellets of turmeric and neem were applied at different doses to determine the field dose of herbal pesticides for repelling insects, during the storage of dry fish. Turmeric and neem extract were applied to the dry fish at the rate of $2,3,4 \%$ and 3,5 and $7 \%$ respectively. Powder and pellet of the two herbs were used at the concentration of 1.0, 1.5 and $2.0 \%$ and 1, 2, 3 pellets per $100 \mathrm{~g}$ dry fish pack. The treated and control dry fishes were kept in polyethylene bags at room temperature $\left(30.3 \pm 2.4^{\circ} \mathrm{C}\right)$ with the mouth of the bag open to allow the movement of insects. One part of the dry fish processed by the same method was also packaged airtight in polythene bags and kept in a refrigerator $\left(5^{\circ} \mathrm{C}\right)$.

\section{Keeping quality of dry fish treated with turmeric and neem}

Keeping quality of dry fish treated with turmeric and neem products at room and refrigeration temperatures was investigated by sensory test (color, odor, texture, general appearance), physical test (occurrence of insects), total volatile base nitrogen (TVB-N) concentration and microbial load determination.

\section{Sensory evaluation}

Color, odor, texture and general appearance of the dry fish treated with turmeric and neem products were evaluated organoleptically. Data were taken at 1 month interval up to 4 months. For color, odor, texture and general appearance sensory score 1 to 10 was used. The scores for color were: 1-2: bright silvery color; 3-5: silvery to yellowish color; 6-7: brown color; 8-10: brown to dark color. The scores for odor were: 1-2: characteristic fishy odor; 3-5: slight decrease of dry fish odor; 6-7: moderate fishy dry fish odor; 8-10: prominence of herbal odor/absence of dry fish odor. For texture the scores were: 1-2: firm and elastic; 3-5: some loss of firmness and elasticity; 6-7: fragile; 8-10: fragmented.

\section{Sensory evaluation of herbal pesticide-treated cooked dry-fish by the panel test}

A trained panel of eleven-person of students, teachers and staffs of the Department of Fisheries Technology provided the sensory assessment of neem and turmeric treated cooked dry fish (Nowsad et al., 2000). Prior to testing, panelist were familiarized with the properties of treated dry-fish and the instructions relating to scoring of the samples. Pretests were done with selected samples to familiarize the panelists with the measurement procedure. Eleven types of cooked dry fish samples including control were supplied to each panelist to recognize every attribute on the score sheet. Sensory scores of 1 to 5 was used, 1 being the natural and 5 being the extreme characteristics.

\section{Statistical analysis}

The experimental data were statistically analyzed by completely randomized design (factorial CRD) using MSTAT statistical software in a computer. The mean values were compared by Duncan's Multiple Range Test (DMRT) (Duncan, 1951).

\section{Results and Discussion}

Repellent effect of turmeric and neem extracts, powder and pellet on Necrobia sp. (adult) Repellency rate of turmeric and neem extracts, powder and pellet at different hours after treatment are presented in Table 1 to Table 3. Repellency rate was recorded at 1 hour, 2 hour, 3 hour, 4 hour and 5 hour after treatment. 
To determine the repellency rate of turmeric and neem extract doses used were 2, 3 and $4 \%$ and 3,5 and $7 \%$ respectively. Highest mean repellency (56.333) was found with $4 \%$ turmeric extract and the lowest mean repellency (30.66) was found with $3 \%$ neem extract. For turmeric and neem powders, doses used were 1.0, 1.50, and $2.00 \%$. The rate of repellency increased with increasing doses. Highest mean repellency (54.333) was found with $2.0 \%$ turmeric powder and the lowest mean repellency (27.333) was found with $1.0 \%$ neem powder. For turmeric and neem pellet, on the other hand, the doses used were 1 , 2 , and 3 pellets per $100 \mathrm{~g}$ dry fish. Likewise aqueous extract and powder, repellency increased with increasing number of pellet. Highest mean repellency (50.000) was found with 3 turmeric and neem pellets and the lowest mean repellency (26.667) was found with 1 pellet. Repellency rate increased with higher dose of turmeric and neem, (turemeric contain concentrate amount curcuminoids and neem contain azadirachtins, salanin and nimbin) which is similar to findings of (Nowsad et al., 2010). From the above results, it was found that extract, powder and pellet of turmeric at highest concentration showed more repellent effect than those of neem.

Table 1. Repellent effect of turmeric and neem extracts at different dose level on Necrobia sp. using crushed dried fish at different HAT (interaction of plant, dose and time)

\begin{tabular}{|c|l|l|l|l|l|l|}
\hline \multirow{2}{*}{$\begin{array}{c}\text { Name of The } \\
\text { Plants }\end{array}$} & Doses (\%) & \multicolumn{5}{|c|}{ Repellency Rate } \\
\cline { 2 - 6 } & & 1 HAT & 2 HAT & 3 HAT & 4 HAT & 5 HAT \\
\hline \multirow{2}{*}{$\begin{array}{c}\text { Turmeric } \\
\text { extract }\end{array}$} & 2 & 21.667 & 26.667 & 31.667 & 41.667 & 46.667 \\
\cline { 2 - 6 } & 3 & 21.667 & 31.667 & 40.000 & 45.000 & 48.333 \\
\cline { 2 - 6 } & 4 & 36.667 & 46.667 & 56.667 & 66.667 & 75.000 \\
\hline \multirow{2}{*}{$\begin{array}{c}\text { Neem } \\
\text { extract }\end{array}$} & 3 & 18.333 & 25.000 & 31.667 & 36.667 & 41.667 \\
\cline { 2 - 6 } & 5 & 18.333 & 26.667 & 36.667 & 43.333 & 46.666 \\
\cline { 2 - 6 } & 7 & 35.000 & 45.000 & 55.000 & 63.333 & 71.667 \\
\hline
\end{tabular}

Table 2. Repellent effect of turmeric and neem powder at different dose level on Necrobia sp. using crushed dried fish at different HAT (interaction of plant, dose and time)

\begin{tabular}{|c|l|l|l|l|l|l|}
\hline Name of The & Doses & \multicolumn{5}{|c|}{ Repellency Rate } \\
\cline { 3 - 7 } Plants & $(\%)$ & 1 HAT & 2 HAT & 3 HAT & 4 HAT & 5 HAT \\
\hline \multirow{3}{*}{$\begin{array}{c}\text { Turmeric } \\
\text { powder }\end{array}$} & 1.0 & 20.000 & 25.000 & 35.000 & 41.667 & 46.667 \\
\cline { 2 - 7 } & 1.5 & 26.667 & 35.000 & 40.000 & 46.667 & 50.000 \\
\cline { 2 - 7 } & 2.0 & 38.333 & 46.667 & 55.000 & 61.667 & 70.000 \\
\hline \multirow{3}{*}{\begin{tabular}{l} 
Neem powder \\
\cline { 2 - 7 }
\end{tabular}} & 1.0 & 16.667 & 21.667 & 26.667 & 33.333 & 38.333 \\
\cline { 2 - 7 } & 1.5 & 26.667 & 33.333 & 38.333 & 45.000 & 50.000 \\
\cline { 2 - 7 } & 2.0 & 35.000 & 45.000 & 53.333 & 60.000 & 66.667 \\
\hline
\end{tabular}

Table 3. Repellent effect of turmeric and neem pellets at different dose level on Necrobia sp. using crushed dried fish at different HAT (interaction of plant, dose and time)

\begin{tabular}{|c|c|c|c|c|c|c|}
\hline Name of The & Doses & \multicolumn{5}{|c|}{ Repellency Rate } \\
\cline { 2 - 6 } Plants & (Number) & 1 HAT & 2 HAT & 3 HAT & 4 HAT & 5 HAT \\
\hline \multirow{3}{*}{$\begin{array}{c}\text { Turmeric Flat } \\
\text { pellet }\end{array}$} & 1 & 21.667 & 26.667 & 33.333 & 40.000 & 45.000 \\
\cline { 2 - 7 } & 2 & 21.667 & 31.667 & 38.333 & 46.667 & 51.667 \\
\hline \multirow{3}{*}{$\begin{array}{c}\text { Neem Flat } \\
\text { pellet }\end{array}$} & 3 & 30.000 & 40.000 & 50.000 & 60.000 & 70.000 \\
\cline { 2 - 7 } & 1 & 15.000 & 20.000 & 26.667 & 33.333 & 38.333 \\
\cline { 2 - 7 } & 2 & 20.000 & 28.333 & 36.667 & 43.333 & 48.333 \\
\hline
\end{tabular}

HAT $=$ Hours after treatment

Mean repellency values within the column followed by different superscripts are significantly different $(p<0.05)$. 
Repellency rate of turmeric and neem aqueous extracts, powder and pellet on Necrobia sp. increased with time and dose presented in Fig. 1 to 3. The interaction effects of dose and time had significant effect on the repellency of Necrobia sp.

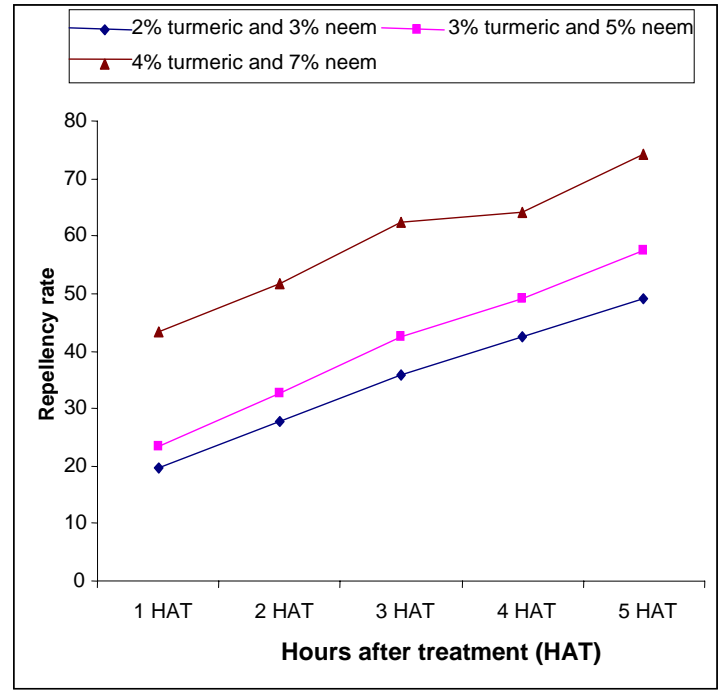

Fig. 1. Repellent effect of turmeric and neem extracts on Necrobia sp. increased with time and dose

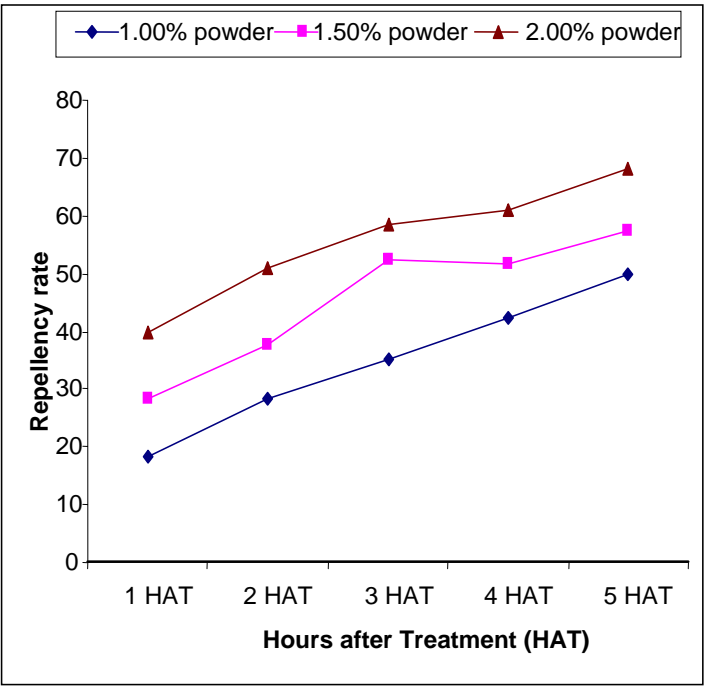

Fig. 2. Repellent effect of turmeric and neem powders on Necrobia sp. increased with time and dose

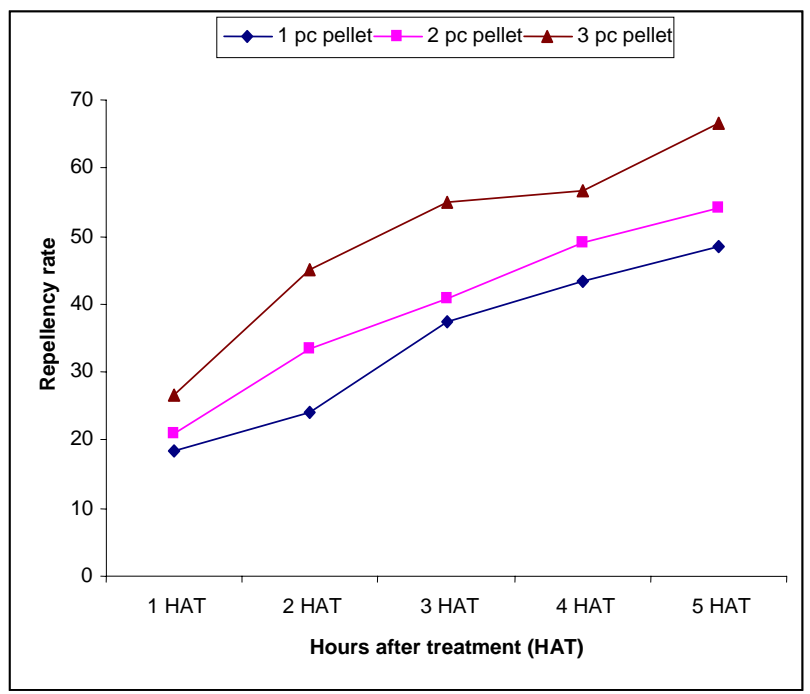

Fig. 3. Repellent effect of turmeric and neem pellets on Necrobia sp. increased with time and dose

\section{Changes in the sensory quality of stored dry fish treated with neem and turmeric}

Neem and turmeric in three forms, viz., aqueous extract, powder and pellet, were applied to the dry fish (Puntius sophore) prepared in the laboratory, packaged in different forms and stored in the laboratory (room temperature: $30.3 \pm 2.4^{\circ} \mathrm{C}$ ) and in a refrigerator $\left(5^{\circ} \mathrm{C}\right)$. Changes in color, odor, texture, general appearance and occurrence of insects in untreated control and treated dry fish at room temperature are shown in Table 4. 
Table 4. Sensory quality of treated dry fish in storage condition

\begin{tabular}{|c|c|c|c|c|c|c|c|c|c|c|c|}
\hline \multirow{3}{*}{$\begin{array}{l}\text { Treated } \\
\text { dry fish }\end{array}$} & \multirow[t]{3}{*}{ Dose } & \multicolumn{10}{|c|}{ Storage period (month) } \\
\hline & & \multicolumn{5}{|c|}{2} & \multicolumn{5}{|c|}{4} \\
\hline & & Colour & Odour & Texture & $\begin{array}{c}\text { General } \\
\text { Appearance }\end{array}$ & \begin{tabular}{|c|} 
Insect \\
(No./Pkt)
\end{tabular} & Colour & Odour & Texture & \begin{tabular}{|c|} 
General \\
Appearance
\end{tabular} & $\begin{array}{c}\text { Insect } \\
\text { (No./Pkt) }\end{array}$ \\
\hline \multicolumn{2}{|l|}{ Control } & $1.6 \pm 0.2$ & $1.3 \pm 0.6$ & $1.3 \pm 0.1$ & $1.6 \pm 0.2$ & $3 \pm 0$ & $7.3 \pm 0.3$ & $4.6 \pm 0.4$ & $4.8 \pm 0.3$ & $5.0 \pm 0.0$ & $7 \pm 1$ \\
\hline \multirow{3}{*}{$\begin{array}{l}\text { Turmeric } \\
\text { extract }\end{array}$} & $2.0 \%$ & $2.3 \pm 0.2$ & $2.3 \pm 0.6$ & $1.5 \pm 0.2$ & $2.0 \pm 0.0$ & 0 & $4.0 \pm 0.0$ & $2.8 \pm 0.3$ & $3.2 \pm 0.0$ & $2.8 \pm 0.0$ & 0 \\
\hline & $3.0 \%$ & $3.3 \pm 0.1$ & $2.6 \pm 0.3$ & $1.6 \pm 0.0$ & $1.8 \pm 0.3$ & 0 & $3.6 \pm 0.3$ & $2 . .3 \pm 0.3$ & $2.7 \pm 0.0$ & $2.3 \pm 0.3$ & 0 \\
\hline & $4.0 \%$ & $3.0 \pm 0.2$ & $2.3 \pm 0.2$ & $1.8 \pm 0.1$ & $2.3 \pm 0.2$ & 0 & $4.3 \pm 0.2$ & $2.3 \pm 0.2$ & $2.6 \pm 0.3$ & $2.0 \pm 0.1$ & 0 \\
\hline \multirow{3}{*}{$\begin{array}{l}\text { Turmeric } \\
\text { powder }\end{array}$} & $1.0 \%$ & $3.6 \pm 0.2$ & $2.6 \pm 0.2$ & $1.3 \pm 0.1$ & $1.3 \pm 0.2$ & 0 & $3.6 \pm 0.3$ & $3.5 \pm 0.3$ & $2.8 \pm 0.3$ & $2.6 \pm 0.3$ & 0 \\
\hline & $1.5 \%$ & $3.6 \pm 0.3$ & $2.1 \pm 0.3$ & $1.6 \pm 0.3$ & $2.0 \pm 1.0$ & 0 & $4.0 \pm 0.0$ & $2.0 \pm 0.0$ & $2.3 \pm 0.2$ & $2.0 \pm 0.2$ & 0 \\
\hline & $2.0 \%$ & $3.7 \pm 0.3$ & $2.5 \pm 0.0$ & $2.0 \pm 0.0$ & $2.3 \pm 0.6$ & 0 & $3.6 \pm 0.3$ & $2.2 \pm 0.3$ & $2.4 \pm 0.3$ & $2.1 \pm 0.2$ & 0 \\
\hline \multirow{3}{*}{$\begin{array}{l}\text { Turmeric } \\
\text { pellet }\end{array}$} & $1 \mathrm{pc}$ & $1.0 \pm 0.0$ & $2.8 \pm 0.1$ & $2.3 \pm 0.2$ & $1.6 \pm 0.6$ & 0 & $5.0 \pm 0.0$ & $3.0 \pm 0.1$ & $3.0 \pm 0.1$ & $4.3 \pm 0.2$ & $4 \pm 1$ \\
\hline & $2 \mathrm{pc}$ & $1.3 \pm 0.2$ & $2.3 \pm 0.6$ & $2.0 \pm 1.0$ & $2.4 \pm 1.0$ & 0 & $5.6 \pm 0.3$ & $2.6 \pm 0.3$ & $3.2 \pm 0.2$ & $4.6 \pm 0.3$ & $1 \pm 0$ \\
\hline & $3 \mathrm{pc}$ & $2.0 \pm 1.0$ & $2.3 \pm 0.6$ & $2.3 \pm 0.1$ & $1.3 \pm 0.1$ & 0 & $5.0 \pm 0.0$ & $2.6 \pm 0.1$ & $3.6 \pm 0.2$ & $3.6 \pm 0.3$ & 0 \\
\hline \multirow{3}{*}{$\begin{array}{l}\text { Neem } \\
\text { extract }\end{array}$} & $3.0 \%$ & $4.6 \pm 0.3$ & $2.4 \pm 0.6$ & $2.3 \pm 0.1$ & $1.8 \pm 0.0$ & 0 & $6.6 \pm 0.3$ & $2.9 \pm 1.0$ & $2.8 \pm 1.0$ & $2.3 \pm 0.6$ & 0 \\
\hline & $5.0 \%$ & $5.0 \pm 1.0$ & $2.0 \pm 0.0$ & $2.0 \pm 1.0$ & $1.6 \pm 0.3$ & 0 & $7.6 \pm 0.4$ & $2.6 \pm 0.3$ & $2.3 \pm 0.2$ & $2.0 \pm 0.0$ & 0 \\
\hline & $7.0 \%$ & $4.0 \pm 0.0$ & $2.3 \pm 0.2$ & $1.6 \pm 0.3$ & $1 . .3 \pm 0.0$ & 0 & $8.6 \pm 0.3$ & $2.6 \pm 0.3$ & $2.0 \pm 0.0$ & $2.2 \pm 0.3$ & 0 \\
\hline \multirow{3}{*}{$\begin{array}{l}\text { Neem } \\
\text { powder }\end{array}$} & $1.0 \%$ & $5.0 \pm 0.0$ & $2.0 \pm 1.0$ & $2.0 \pm 1.0$ & $2.3 \pm 0.1$ & 0 & $7.0 \pm 1.0$ & $3.6 \pm 0.3$ & $2.0 \pm 1.0$ & $3.6 \pm 0.3$ & 0 \\
\hline & $1.5 \%$ & $5.6 \pm 0.3$ & $2.6 \pm 0.3$ & $1.6 \pm 0.3$ & $2.6 \pm 0.3$ & 0 & $7.3 \pm 0.2$ & $3.3 \pm 0.6$ & $1.9 \pm 0.2$ & $2.3 \pm 0.6$ & 0 \\
\hline & $2.0 \%$ & $4.6 \pm 0.3$ & $2.0 \pm 0.0$ & $1.3 \pm 0.1$ & $1.8 \pm 0.3$ & 0 & $7.6 \pm 0.3$ & $2.6 \pm 0.3$ & $1.6 \pm 0.3$ & $2.0 \pm 0.0$ & 0 \\
\hline \multirow{3}{*}{$\begin{array}{l}\text { Neem } \\
\text { pellet }\end{array}$} & $1 \mathrm{pc}$ & $3.0 \pm 0.1$ & $2.3 \pm 0.1$ & $2.4 \pm 0.2$ & $2.0 \pm 0.3$ & 0 & $4.0 \pm 1.0$ & $4.3 \pm 0.6$ & $3.3 \pm 0.2$ & $3.3 \pm 0.6$ & $3 \pm 1$ \\
\hline & $2 \mathrm{pc}$ & $3.0 \pm 0.0$ & $2.6 \pm 0.3$ & $2.2 \pm 0.2$ & $1.7 \pm 0.2$ & 0 & $4.5 \pm 0.1$ & $3.6 \pm 0.3$ & $3.3 \pm 0.2$ & $3.6 \pm 0.3$ & $2 \pm 0$ \\
\hline & $3 \mathrm{pc}$ & $3.6 \pm 0.3$ & $2.5 \pm 0.0$ & $2.6 \pm 0.3$ & $1.6 \pm 0.1$ & 0 & $4.6 \pm 0.3$ & $4.0 \pm 0.0$ & $2.3 \pm 0.3$ & $4.0 \pm 0.0$ & $2 \pm 0$ \\
\hline
\end{tabular}

The data for 2 and 4 month storage of control and treated dry fish have been presented. The color, odor, texture and general appearance of the untreated control and treated dry fish were almost similar after 2 month of storage at room temperature. There were some changes in color and odor after 2 months due to application of turmeric and neem, but the general appearance and the texture of the products were quite acceptable. Application of neem extract and powder, however, changed the color of the products towards brown to dark. Color became more yellowish to brownish to dark when higher doses of turmeric or neem were used. The characteristic dry fish odor, however, persisted all along the doses applied. No insect attack was observed after 2 months in turmeric or neem treated dry fish, but untreated controlled was attacked by beetle ( 3 insects). After 4 month of storage, however, the sensory attributes like odor, texture and general appearance and the occurrence of insects in control dry fish fell sharply. On the other hand, these attributes were not so declined in turmeric/neem treated ones after 4 months. From the repellency tests, it was understood that the turmeric extract and powder were more repellent than neem extract and powder. Therefore, we applied higher doses of neem extract $(3,5$ and $7 \%)$ than the turmeric extract $(2,3$ and $4 \%)$. Sensory color quality deteriorated with increased concentrations of both turmeric and neem, with neem being aggressively responsible for unacceptable brownish to dark color of the products. The application of higher doses of neem and turmeric extract and powder, although improved the keeping quality but reduced the sensory attributes of the products. Untreated control dry fish was severely attacked by Necrobia beetle after 4 months, dry fish treated with turmeric and neem extract and powder were not attacked. On the other hand, both the pellets were found less effective against the beetle attack, since 4 and 1 insects were found in dry fish treated with $1 \mathrm{pc}$ and 2 pc of turmeric pellet or 3,2 and 2 insects were found in dry fish treated with 1 pc, 2 pc and 3 pc neem pellet, respectively.

The treated and control dry fish kept at refrigerated temperature were neither attacked by the insects nor their sensory qualities were deteriorated except that of color quality lost due to direct application of turmeric or neem powders or extracts, as explained above for the products kept at room temperature. 


\section{Changes in Total volatile base nitrogen (TVB-N) value $(\mathrm{mg} / \mathbf{1 0 0 \mathrm { g }})$ of controlled and treated dry fish}

Total volatile base nitrogen (TVB-N) is a commonly used chemical method to determine the quality of fish and dry fish. The TVB-N values of the dry fish stored in room temperature $\left(30.3 \pm 2.4^{\circ} \mathrm{C}\right)$ and refrigeration temperatures $\left(5^{\circ} \mathrm{C}\right.$ ) have been presented in Fig. 4 and 5 . Middle doses of both turmeric (3\% extract, $1.5 \%$ powder, 2 pellets) and neem (5\% extract, $1.5 \%$ powder and 2 pellets) were used. TVB-N value increased progressively throughout the storage period. TVB- $N$ value of treated and control dry fish increased more rapidly at ambient room temperature (Fig. 4) where TVB-N value of treated and control dry fish increased slowly in refrigeration temperature (Fig. 5). As storage period increased, TVB-N value was increased. Neem and turmeric products and their different doses applied in dry fish during storage period had no significant effect on rapid change of TVB-N values.

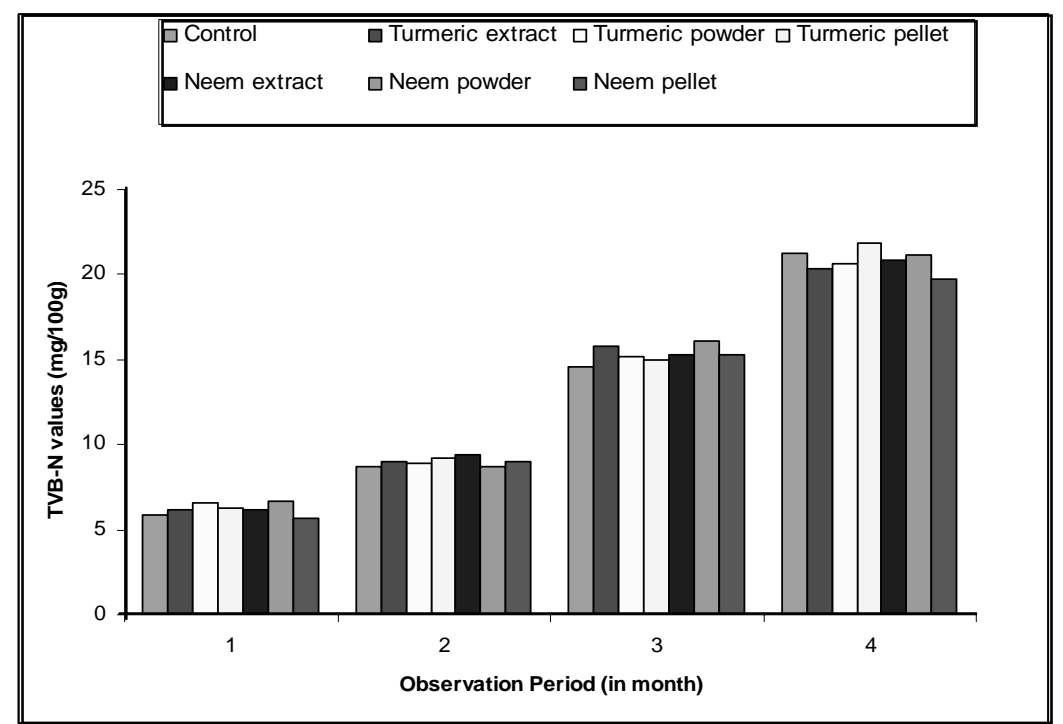

Fig. 4. Changes in TVB-N value $(\mathrm{mg} / 100 \mathrm{~g})$ in control and treated dry fish in room temperature $\left(30.3 \pm 2.4^{\circ} \mathrm{C}\right)$

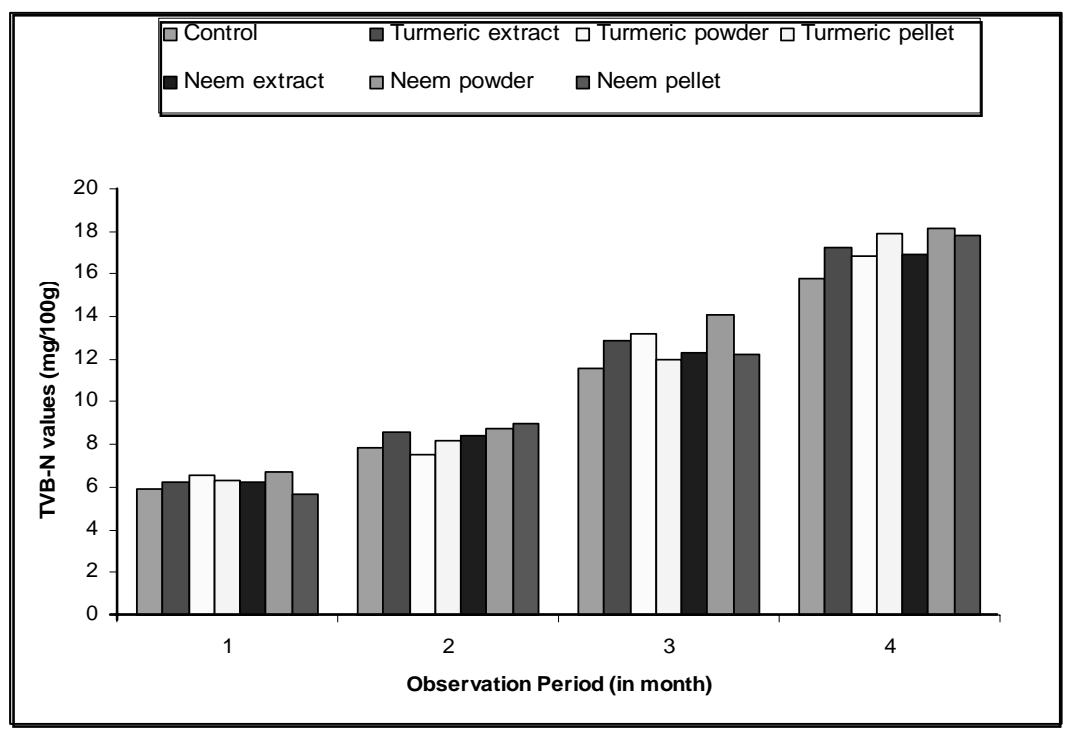

Fig. 5. Changes in TVB-N value $(\mathrm{mg} / 100 \mathrm{~g})$ in control and treated dry fish in refrigeration temperature $\left(5^{\circ} \mathrm{C}\right)$ 


\section{Changes in microbial load of the treated dry fish}

The microbiological quality of the control and treated products were investigated. The treated dry fish were stored in room $\left(30.3 \pm 2.4^{\circ} \mathrm{C}\right)$ and refrigeration temperatures $\left(5^{\circ} \mathrm{C}\right)$, results were been presented in Table 5.

Table 5. Changes in the aerobic plate count (APC) of control and treated dry fish stored at room $\left(30.3 \pm 2.4^{\circ} \mathrm{C}\right)$ and refrigeration temperatures $\left(5^{\circ} \mathrm{C}\right)$

\begin{tabular}{|c|c|c|c|c|c|c|c|c|c|}
\hline \multirow{4}{*}{ Product name } & \multirow{4}{*}{ Dose } & \multirow{2}{*}{\multicolumn{4}{|c|}{$\begin{array}{c}\text { Room temperature }\left(30.3 \pm 2.4^{\circ} \mathrm{C}\right) \\
\text { Storage period (month) }\end{array}$}} & \multirow{2}{*}{\multicolumn{4}{|c|}{$\begin{array}{c}\text { Refrigeration temperatures }\left(5^{\circ} \mathrm{C}\right) \\
\text { Storage period (month) }\end{array}$}} \\
\hline & & & & & & & & & \\
\hline & & \multicolumn{2}{|c|}{1} & \multicolumn{2}{|c|}{4} & \multicolumn{2}{|c|}{ - } & \multicolumn{2}{|c|}{4} \\
\hline & & $\mathrm{CFU} / \mathrm{g}$ & $\begin{array}{l}\mathrm{Log} \\
\mathrm{CFU} / \mathrm{g}\end{array}$ & $\mathrm{CFU} / \mathrm{g}$ & $\begin{array}{l}\log \\
\mathrm{CFU} / \mathrm{g}\end{array}$ & $\mathrm{CFU} / \mathrm{g}$ & $\begin{array}{l}\log \\
\text { CFU/g }\end{array}$ & CFU/g & $\begin{array}{l}\mathrm{Log} \\
\mathrm{CFU} / \mathrm{g}\end{array}$ \\
\hline \multicolumn{2}{|l|}{ Control } & $5.9 \times 10^{5}$ & 5.77 & $7.9 \times 10^{5}$ & 5.89 & $6.1 \times 10^{4}$ & 4.78 & $6.2 \times 10^{5}$ & 5.79 \\
\hline \multirow[t]{3}{*}{ Turmeric extract } & $2.0 \%$ & $4.3 \times 10^{3}$ & 3.63 & $5.1 \times 10^{4}$ & 4.70 & $3.4 \times 10^{3}$ & 3.53 & $3.5 \times 10^{4}$ & 4.54 \\
\hline & $3.0 \%$ & $3.6 \times 10^{3}$ & 3.55 & $4.8 \times 10^{4}$ & 4.68 & $2.9 \times 10^{3}$ & 3.46 & $4.0 \times 10^{4}$ & 4.60 \\
\hline & $4.0 \%$ & $2.9 \times 10^{3}$ & 3.46 & $3.9 \times 10^{4}$ & 4.59 & $2.8 \times 10^{3}$ & 3.44 & $4.2 \times 10^{4}$ & 4.62 \\
\hline \multirow[t]{3}{*}{ Turmeric powder } & $1.0 \%$ & $4.5 \times 10^{3}$ & 3.65 & $5.8 \times 10^{5}$ & 5.76 & $3.6 \times 10^{3}$ & 3.55 & $3.8 \times 10^{4}$ & 4.57 \\
\hline & $1.5 \%$ & $3.7 \times 10^{3}$ & 3.56 & $5.2 \times 10^{4}$ & 4.71 & $3.2 \times 10^{3}$ & 3.50 & $4.2 \times 10^{4}$ & 4.62 \\
\hline & $2.0 \%$ & $2.8 \times 10^{3}$ & 3.44 & $4.5 \times 10^{4}$ & 4.65 & $3.2 \times 10^{3}$ & 3.50 & $4.5 \times 10^{4}$ & 4.65 \\
\hline \multirow[t]{3}{*}{ Turmeric pellet } & $1 \mathrm{pc}$ & $4.9 \times 10^{3}$ & 3.69 & $6.7 \times 10^{4}$ & 4.79 & $3.8 \times 10^{3}$ & 3.57 & $4.0 \times 10^{4}$ & 4.60 \\
\hline & $2 p c$ & $4.3 \times 10^{3}$ & 3.63 & $6.4 \times 10^{4}$ & 4.80 & $3.6 \times 10^{3}$ & 3.55 & $4.5 \times 10^{4}$ & 4.65 \\
\hline & $3 \mathrm{pc}$ & $3.8 \times 10^{3}$ & 3.57 & $4.3 \times 10^{4}$ & 4.63 & $3.4 \times 10^{3}$ & 3.53 & $4.8 \times 10^{4}$ & 4.67 \\
\hline \multirow[t]{3}{*}{ Neem extract } & $3.0 \%$ & $3.5 \times 10^{4}$ & 4.54 & $5.4 \times 10^{4}$ & 4.73 & $3.6 \times 10^{3}$ & 3.55 & $6.4 \times 10^{4}$ & 4.80 \\
\hline & $5.0 \%$ & $3.8 \times 10^{3}$ & 3.57 & $4.7 \times 10^{4}$ & 4.67 & $2.7 \times 10^{3}$ & 3.43 & $5.7 \times 10^{4}$ & 4.75 \\
\hline & $7.0 \%$ & $2.9 \times 10^{3}$ & 3.46 & $3.8 \times 10^{4}$ & 4.57 & $2.5 \times 10^{3}$ & 3.39 & $4.8 \times 10^{4}$ & 4.67 \\
\hline \multirow{3}{*}{ Neem powder } & $1.0 \%$ & $3.8 \times 10^{4}$ & 4.57 & $5.4 \times 10^{5}$ & 5.72 & $3.8 \times 10^{3}$ & 3.57 & $6.7 \times 10^{4}$ & 4.82 \\
\hline & $1.5 \%$ & $4.7 \times 10^{3}$ & 3.67 & $5.1 \times 10^{4}$ & 4.70 & $3.3 \times 10^{3}$ & 3.51 & $5.9 \times 10^{4}$ & 4.77 \\
\hline & $2.0 \%$ & $2.7 \times 10^{3}$ & 3.43 & $4.2 \times 10^{3}$ & 3.62 & $2.8 \times 10^{3}$ & 3.44 & $5.0 \times 10^{4}$ & 4.69 \\
\hline \multirow[t]{3}{*}{ Neem pellet } & $1 \mathrm{pc}$ & $4.7 \times 10^{4}$ & 4.67 & $6.2 \times 10^{5}$ & 5.79 & $2.8 \times 10^{4}$ & 4.44 & $7.2 \times 10^{4}$ & 4.85 \\
\hline & $2 \mathrm{pc}$ & $3.3 \times 10^{4}$ & 4.51 & $5.9 \times 10^{4}$ & 4.77 & $2.5 \times 10^{4}$ & 4.39 & $6.2 \times 10^{4}$ & 4.79 \\
\hline & $3 \mathrm{pc}$ & $2.9 \times 10^{3}$ & 3.46 & $5.3 \times 10^{4}$ & 4.72 & $2.2 \times 10^{3}$ & 3.34 & $5.5 \times 10^{4}$ & 4.71 \\
\hline
\end{tabular}

The aerobic plate count (APC) was in quite acceptable range all along the storage period at room temperature in all treated dry fish. After 4 month of storage, an increment of APC values were observed, up to $5.89 \log$ CFU/g in control dry fish. Application of turmeric and neem extract and powders reduced the APC values both after 1 month and 4 months. All these values were within the acceptable limit of the dry fish APC content. Extracts and powders of turmeric and neem equally showed better effect on microbial load since similar reduced APC values were observed. On the other hand, pellets of turmeric and neem showed comparatively higher APC values than extracts and powders, but the values were much lower than the untreated control and still in good acceptable range. Investigation showed that APC values decreased with increased doses of extracts and powders. But since all these values were in safe range, comparatively lower doses could be suggested for treatment of dry fish as field dose, considering other important factors like occurrence of insects, color, taste (panel test) and consumer appeal (general appearance).

Treated dry fish stored at refrigerator showed much lower APC values than those stored at room temperature (Table 5). Similar trend of lowering APC in terms of higher doses of extract, powder or pellet, as in case of storing at room temperature, were observed. Both extracts and powders were better than pellets. Turmeric was better than neem. APC values matched well with the repellency test results. Since all of doses obtained acceptable APC valued, a middle dose could be better while considering the sensory appeal of the treated products. 


\section{Sensory panel test of herbal pesticide-treated cooked dry-fish for determination of consumer acceptance}

A trained panel of eleven-person of students, teachers and staffs of the Department of Fisheries Technology provided the sensory panel test of herbal pesticide-treated cooked dry-fish (Nowsad et al., 2000). Eleven types of cooked dry-fish samples including control and herbal pesticide-added cooked dryfish were supplied to each panelist to chew, shallow and then eat and finally to recognize every attribute. Responses of panelists were divided in to five categories such as excellent, good, average, bad and very bad. Result shows that high doses of turmeric (4\% extract, $2 \%$ powder, 3 pellets) and neem (7\% extract, $2 \%$ powder, 3 pellets) had significant negative effect on color, flavor and taste of cooked dry-fish and obtained average cooked products in terms of color, flavor and taste. On the other hand, middle doses of turmeric (3\% extract, $1.5 \%$ powder, 2 pellets) and neem (5\% extract, $1.5 \%$ powder and 2 pellets) products when applied to the dry fish obtained excellent cooked dry fish in terms of color, flavor and taste with no sense of bitterness produced by either turmeric or neem. Dry fish treated with turmeric obtained better cooked product than those treated with neem.

Therefore, considering the overall panel scores, it was understood that the middle doses of turmeric (3\% extract, $1.5 \%$ powder) or neem ( $5 \%$ extract, $1.5 \%$ powder) could be suitable field doses for application of turmeric or neem in dry fish directly to deter or repel insects while storing the products. Both turmeric and neem in pellet form showed lower repellency effect, while occurrences of insects were comparatively higher, although it produced excellent cooked products.

Table 6. Sensory panel test scores of treated and cooked dry fish

\begin{tabular}{|c|c|c|c|c|}
\hline \multirow[t]{2}{*}{ Cooked dry-fish } & \multicolumn{4}{|c|}{ Sensory Characteristics } \\
\hline & Color & Flavor /Odor & Taste & Comment \\
\hline Control & $1.0 \pm 0.0^{\mathrm{a}}$ & $1.0 \pm 0.0^{\mathrm{a}}$ & $1.09 \pm 0.9^{a}$ & Excellent \\
\hline Powder & & & & \\
\hline $\begin{array}{l}\text { Neem (mid-dose) } \\
\text { Neem (high dose }\end{array}$ & $\begin{array}{l}1.4 \pm 0.4^{\mathrm{a}} \\
3.6 \pm 0.5^{\mathrm{c}}\end{array}$ & $\begin{array}{l}1.4 \pm 0.5^{\mathrm{a}} \\
2.9 \pm 0.3^{\mathrm{bc}}\end{array}$ & $\begin{array}{l}1.45 \pm 0.5^{\mathrm{a}} \\
3.73 \pm 0.4^{\mathrm{c}}\end{array}$ & $\begin{array}{l}\text { Excellent } \\
\text { Average }\end{array}$ \\
\hline $\begin{array}{l}\text { Turmeric (mid-dose) } \\
\text { Turmeric (high dose) }\end{array}$ & $\begin{array}{l}1.0 \pm 0.0^{a} \\
2.7 \pm 0.3^{b}\end{array}$ & $\begin{array}{l}1.3 \pm 0.4^{\mathrm{a}} \\
2.2 \pm 0.4^{\mathrm{b}}\end{array}$ & $\begin{array}{l}1.36 \pm 0.6 \\
3.01 \pm 0.2^{b c}\end{array}$ & $\begin{array}{l}\text { Excellent } \\
\text { Average }\end{array}$ \\
\hline Aqueous Extract & & & & \\
\hline $\begin{array}{l}\text { Neem (mid- dose) } \\
\text { Neem (high dose) }\end{array}$ & $\begin{array}{l}1.1 \pm 0.0^{\mathrm{a}} \\
3.4 \pm 0.6^{\mathrm{c}}\end{array}$ & $\begin{array}{l}1.5 \pm 0.4^{\mathrm{a}} \\
3.2 \pm 0.6^{\mathrm{bc}}\end{array}$ & $\begin{array}{l}1.72 \pm 0.3^{a} \\
2.8 \pm 0.5^{b}\end{array}$ & $\begin{array}{l}\text { Excellent } \\
\text { Average }\end{array}$ \\
\hline $\begin{array}{l}\text { Turmeric (mid-dose) } \\
\text { Turmeric (high dose) }\end{array}$ & $\begin{array}{l}1.0 \pm 0.0^{a} \\
2.2 \pm 0.3^{b}\end{array}$ & $\begin{array}{l}1.1 \pm 0.3^{\mathrm{a}} \\
2.0 \pm 0.4^{\mathrm{b}}\end{array}$ & $\begin{array}{l}1.36 \pm 0.6^{\mathrm{a}} \\
2.9 \pm 0.6^{\mathrm{bc}}\end{array}$ & $\begin{array}{l}\text { Excellent } \\
\text { Average }\end{array}$ \\
\hline Flat pellet & & & & \\
\hline Neem (mid-dose) & $1.0 \pm 0.0^{\mathrm{a}}$ & $1.3 \pm 0.7^{\mathrm{a}}$ & $1.27 \pm 0.7^{\mathrm{a}}$ & Excellent \\
\hline Turmeric (mid-dose) & $1.2 \pm 0.8^{a}$ & $1.2 \pm 0.8^{a}$ & $1.3 \pm 0.7^{\mathrm{a}}$ & Excellent \\
\hline
\end{tabular}

Score: $1=$ excellent, $2=$ good, $3=$ average, $4=$ bad, $5=$ very bad;

High dose for turmeric - 4\% extract, $2 \%$ powder, 3 pellets and for neem-7\% extract, $2 \%$ powder, 3 pellets;

Mid-dose for turmeric - 3\% extract, 1.5\% powder, 2 pellets and for neem-5\% extract, 1.5\% powder and 2 pellets;

Figures with different superscripts in different columns and rows differ significantly $(p<0.05)$.

\section{References}

Ascher, K.R.S. 1993. Non-conventional insecticidal effects of pesticides available from the neem tree, Azadirachta indica. Archives of Insect Biochemistry ahemical pollutants, The New Nation, Internet Edn. Nov., http://nation.ittefaq.com/rss.xml.

Bala, B.K. and Mondol, M.R.A. 2001. Experimental Investigation of solar drying of using tunnel dryer, Drying Technology, 19(2): 1-10.

BBS. 2005. Bangladesh Bureau of Statistics. Ministry of Planning. Peoples Republic of Bangladesh, Dhaka.

DoF. 2010. Department of Fisheries. Annual report. Matsaya Bhaban, Dhaka. 
Don-Pedro, K.N. 1989. Insecticidal activity of some vegetable oils against D. maculates, Degeer Coleoptera; Dermestidae on dried fish. Stored Prod. Res., 25 (2): 81-86.

Duncan, D.B. 1951. A significance test for differences between ranked treatments in an analysis of variance. Virginia. J. Sci., 2(9): 171-189.

Kordyl, E. 1976. Some protective measures against insect infestation of dried fish in Africa. Proceedings of the Conference on Handling, Processing and Marketing of Tropical Fish, Tropical Products Institute, London, UK. pp. 313-314.

Mondol, R. 2008. Suitability of botanical pesticides (neem, garlic and read chili) in the disinfection of insects (beetle and mites) in sun dried fish. M. Sc. thesis, Department of Fisheries Technology, Bangladesh Agricultural University, Mymensingh. pp. 21-56.

Nowsad, A.K.M.A., Hoque, M.E. and Sarker, F.C. 2000. First report of the formulation and development of fish sausage from underutilized marine fish in Bangladesh; fish sausage from sea catfish and Bombay duck. Bangladesh J. Fish., 23(2): 107112.

Nowsad, A.K.M.A. 2005. Low-cost Fish Processing in Costal Bangladesh. BGD/97/017, Field Doc: 5/2005. FAO, 88 p.

Nowsad, A.K.M.A., Mondal, R., Hassan, M.N., Hossain, M.M. and Islam, M.R. 2010. Suitability of some botanical pesticides (neem, garlic and red chili) against dried fish insects (Dermestes sp. Larvae and Necrobia sp. adult). Progress. Agric., 21(1\&2): 93-103.

Neuschler, H. 1998. Fish drying with the solar tunnel dryer type Hohenheim under Bangladesh conditions. Final Research Report. Institute of Agriculture Engineering in the Tropics and Sub-tropics, Hohenheim University, Stuttgart, Germany.

Sundaram, K.M.S. 1996. Azadirachtin Bioprsticide, Bangladesh review of studies conducted on its analytical chemistry, environmental behavior and biological effects. J. Environ. Sci. and Health, 31: 913-948.

Talukder, F.A. and Howse, P.F. 1995. Evaluation of Aphanamixix polystachya as Bangladesh source of repellent, antifeedant, toxicant and protectant in storage against Tribolium costatum Herbst. J. Stored Prod. Res., 31(91): 55-61.

Xie, Y.S., Fields, P.G. and Isman, M.B. 1995. Repellency and toxicity of azadirachtin and neem concentrates to three stored products beetles. J. Econ. Entomol., 88: 1024-1031. 